\title{
Inclusão de ovo desidratado em rações para frangos de corte nas fases pré-inicial e de crescimento
}

\section{Elisanie Neiva Magalhães Teixeira1, José Humberto Vilar da Silva², Marcelo Luís Gomes Ribeiro², Fernando Guilherme Perazzo Costa ${ }^{3}$, José Jordão Filho', Daniel de Magalhães Araujo4}

\author{
${ }^{1}$ Doutorado Integrado em Zootecnia, PIDZ/CCA/UFPB/UFRPE/UFC, Areia - PB. Bolsista da Capes. \\ 2 DAP/CFT/UFPB, Bananeiras - PB e PPGZ - CCA/UFPB, Areia, PB. Bolsista PQ-CNPq. \\ 3 PPGZ/CCA/UFPB, Areia - PB. Bolsista PQ-CNPq. \\ ${ }^{4}$ Doutorado em Zootecnia da FMVZ/UNESP, Botucatu, SP. Bolsista FAPEAL.
}

RESUMO - O experimento foi conduzido para determinar o nível ótimo de inclusão de ovo desidratado (OD) em raçõespara frangos de corte nas fases pré-inicial e de crescimento. Utilizou-se um lote de 1.152 pintos de corte machos, linhagem Cobb-500, com peso vivo inicial de 43,46 $\pm 0,23 \mathrm{~g}$, alojados em boxes de $1,0 \times 1,5 \mathrm{~m}$. O delineamento foi o inteiramente casualizado, com 4 tratamentos $(0 ; 0,5 ; 1,0$ e 1,5\% de ovo desidratado), cada um com 18 repetições de 16 aves. As dietas utlilizadas foram isoprotéicas e isocalóricas, com 21,9\% PB e $2.950 \mathrm{kcal}$ EMAn na fase de 1 a 7 dias e $20,9 \%$ PB e $3.000 \mathrm{kcal}$ EMAn na fase de 8 a 21 dias de idade. O conteúdo dos ovos foi mantido em estufa a $55^{\circ} \mathrm{C}$ durante 72 horas e apresentava resultado negativo para a presença de Salmonella spp. Os níveis de ovo desidratado nas rações tiveram efeito quadrático sobre o consumo de ração, o peso vivo, o ganho de peso e a conversão alimentar. O melhor ganho de peso na fase pré-inicial foi obtido com a utilização de $0,53 \%$ de ovo desidratado na ração e, na fase inicial de crescimento, com o nível de $0,73 \%$.

Palavras-chave: desempenho, ovos trincados, valor nutritivo do ovo

\section{Inclusion of dried egg powder in pre-initial and growing diets of broiler chickens}

\begin{abstract}
The experiment was carried out to determine the optimum inclusion level of dried egg powder (DEGG) in the pre-initial and growing rations of broilers. Male Cobb-500 chicks $(\mathrm{n}=1,152)$ with initial live weight of $43.46 \pm 0.23 \mathrm{~g}$ were housed in cages of $1,0 \times 1,5 \mathrm{~m}$. A completely randomized design with four rations $0,(0.5,1.0$ and $1.5 \%$ of DEGG), each one with 18 replications of 16 birds. Isoproteic and isoenergetic rations were used, with $21.9 \% \mathrm{CP}$ and 2,950 kcal AMEn from 1 to 7 days old and $20.9 \% \mathrm{CP}$ and 3,000 kcal AMEn from 8 to 21 days old. Egg contents were dried at $55^{\circ} \mathrm{C}$ for 72 hours and were negative for Salmonella spp. Dried egg powder inclusion levels showed a quadratic effect on feed intake, live weight, weight gain and feed conversion. Weight gain was obtained with the use of $0.53 \%$ dried egg powder in the ration in the prestarter and $0.73 \%$ in the initial growth phase.
\end{abstract}

Key Words: cracked eggs, egg nutritive value, performance

\section{Introdução}

Em granjas comerciais de postura, uma das principais preocupações é a qualidade externa dos ovos, em virtude dos prejuízos econômicos associados à má qualidade da casca, que resulta em quantidade significativa de subprodutos inadequados ao consumo humano. Segundo Junqueira et al. (2001), ovos trincados mas com membranas intactas e conteúdo constante são comumente utilizados na alimentação humana nas formas líquida, seca ou em pó.

A incidência de ovos com casca quebrada na avicultura de postura é de 6 a $8 \%$ (Washburn, 1982) e, considerando a produção de 22,2 bilhões de unidades (Avicultura Indus- trial, 2005) e o descarte de $3 \%$ dos ovos produzidos no Brasil, estima-se perda superior a 66 milhões de unidades de ovos de $60 \mathrm{~g}$ ou 40 mil toneladas de ovos em casca ou $37 \mathrm{mil}$ toneladas de clara e de gema por ano, um volume expressivo de subprodutos que pode ser aproveitado na alimentação de pintos de corte nas fases pré-inicial e inicial, uma vez que esse volume, quando desidratado, rende 9,1 mil toneladas (Silva et al., 2006). Além disso, Schmidt et al. (2003) citaram que a indústria do ovo líquido descarta aproximadamente $2 \%$ de subprodutos com potencial econômico e nutricional para ser aproveitado na alimentação animal.

O ovo desidratado é um subproduto altamente nutritivo e que fornece $51,54 \%$ de proteína bruta e $4.278 \mathrm{kcal}$ 
de energia metabolizável corrigida pelo balanço de nitrogênio para pintos de corte (por kg de matéria natural), portanto, é $25 \%$ mais energético que o milho e tão rico em proteína quanto o farelo de soja (Teixeira et al., 2005). Além disso, o ovo é considerado excelente fonte de imunoglobulinas e que, normalmente, contém $150 \mathrm{mg}$ de gama globulina por unidade (Harmon et al., 2001), por isso, pode contribuir nutricional e profilaticamente para melhorar o desempenho das aves, uma vez que, na fase pós-eclosão, o metabolismo energético de lipídios predomina sobre o de carboidratos (Dibner, 1997). Poucos estudos, no entanto, têm sido realizados para avaliar a utilização desses ovos em dietas para pintos de corte.

Este trabalho foi realizado para determinar o melhor nível de inclusão de ovo desidratado em dietas para pintos de corte nas fases pré-inicial e inicial de crescimento.

\section{Material e Métodos}

O experimento foi realizado no Aviário Experimental do Setor de Pesquisas em Nutrição de Aves (SNPA), do Centro de Formação de Tecnólogos (CFT), Campus III da Universidade Federal da Paraíba (UFPB), localizado em Bananeiras, microrregião do Brejo Paraibano, no período de junho a julho de 2005.

Utilizou-se um plantel de 1.152 pintos de corte machos, linhagem Cobb-500, alojados em boxes de 1,0 $\mathrm{m} \times 1,5 \mathrm{~m}$, em delineamento inteiramente ao acaso, com quatro tratamentos, cada um com 18 repetições de 16 aves. Os níveis de ovo desidratado na dieta foram $0 ; 0,5 ; 1,0$ e $1,5 \%$. As dietas, todas isoprotéicas e isocalóricas, foram formuladas segundo recomendações de Rostagno et al. (2000). As rações fornecidas na fase de 1 a 7 dias (Tabela 1) continham 21,91\% PB e $2.950 \mathrm{kcal}$ EMn e, na fase de 8 a 21 dias de idade (Tabela 2), 20,87\% PB e 3.000 kcal EMn.

No terceiro dia de idade, foram abatidos 27 pintos (três por parcela) para medições do trato gastrintestinal e análise da carcaça. Avaliaram-se os pesos da carcaça e do peito e seus respectivos músculos, Pectoralis major e Pectoralis minor. A retirada do filé de peito foi realizada manualmente por um único operador e, em seguida, o material foi separado nos músculos Pectoralis major e Pectoralis minor.

Foram avaliados os pesos e comprimentos do tratogastrintestinal, duodeno (DU), jejuno(JE) e íleo (IL) e os pesos da moela (MOE), do intestino delgado (ID), do fígado (FI) e da bolsa de fabricius (BF). As características de desempenho estudadas foram: peso vivo (PV), ganhos de peso diário (GPD) e total (GPT), consumos de ração diário
Tabela 1 - Composição das rações experimentais fornecidas na fase de 1 a 7 dias de idade ${ }^{1}$

\begin{tabular}{|c|c|c|c|c|}
\hline \multirow[b]{2}{*}{ Ingrediente } & \multicolumn{4}{|c|}{ Nível de ovo desidratado nas dietas ${ }^{2}$} \\
\hline & 0,00 & 0,50 & 1,00 & 1,50 \\
\hline Milho & 56,233 & 55,934 & 55,636 & 55,337 \\
\hline Farelo de soja & 36,833 & 36,333 & 35,834 & 35,334 \\
\hline Calcário & 0,997 & 0,997 & 0,997 & 0,997 \\
\hline Fosfato bicálcico & 1,897 & 1,904 & 1,910 & 1,917 \\
\hline Ovo desidratado 2 & 0,000 & 0,500 & 1,000 & 1,500 \\
\hline DL-metionina & 0,253 & 0,250 & 0,246 & 0,243 \\
\hline L-lisina. $\mathrm{HCl}$ & 0,182 & 0,179 & 0,176 & 0,173 \\
\hline Óleo vegetal & 2,500 & 2,500 & 2,500 & 2,500 \\
\hline Premix mineral ${ }^{3}$ & 0,050 & 0,050 & 0,050 & 0,050 \\
\hline Premix vitamínico ${ }^{4}$ & 0,100 & 0,100 & 0,100 & 0,100 \\
\hline Cloreto de colina, $70 \%$ & 0,080 & 0,080 & 0,080 & 0,080 \\
\hline Sal comum & 0,458 & 0,459 & 0,460 & 0,462 \\
\hline Anticoccidiano $^{5}$ & 0,040 & 0,040 & 0,040 & 0,040 \\
\hline $\begin{array}{l}\text { Promotor de } \\
\text { crescimento }^{6}\end{array}$ & 0,015 & 0,015 & 0,015 & 0,015 \\
\hline Antioxidante ${ }^{7}$ & 0,010 & 0,010 & 0,010 & 0,010 \\
\hline Inerte ${ }^{8}$ & 0,352 & 0,649 & 0,946 & 1,242 \\
\hline \multicolumn{5}{|l|}{ Composição química } \\
\hline Proteína bruta $(\%)$ & 21,915 & 21,915 & 21,915 & 21,915 \\
\hline EM (kcal/kg) & 2.950 & 2.950 & 2.950 & 2.950 \\
\hline Cálcio (\%) & 0,988 & 0,988 & 0,988 & 0,988 \\
\hline Fósforo total (\%) & 0,703 & 0,701 & 0,698 & 0,696 \\
\hline Fósforo disponível (\%) & 0,466 & 0,466 & 0,466 & 0,466 \\
\hline Metionina total (\%) & 0,585 & 0,586 & 0,587 & 0,588 \\
\hline Metionina digestível (\%) & 0,555 & 0,556 & 0,557 & 0,588 \\
\hline Met + cis total $(\%)$ & 0,926 & 0,926 & 0,926 & 0,926 \\
\hline Met + cis digestível $(\%)$ & 0,843 & 0,843 & 0,844 & 0,844 \\
\hline Lisina total $(\%)$ & 1,307 & 1,307 & 1,307 & 1,307 \\
\hline Lisina digestível (\%) & 1,187 & 1,187 & 1,187 & 1,187 \\
\hline Treonina total $(\%)$ & 0,841 & 0,842 & 0,843 & 0,843 \\
\hline Treonina digestível (\%) & 0,732 & 0,733 & 0,734 & 0,735 \\
\hline Sódio (\%) & 0,244 & 0,244 & 0,244 & 0,244 \\
\hline Cloro $(\%)$ & 0,305 & 0,305 & 0,306 & 0,306 \\
\hline Potássio (\%) & 0,846 & 0,836 & 0,826 & 0,816 \\
\hline
\end{tabular}

${ }^{1}$ Recomendações de Rostagno et al. (2000).

2 Aminoácido do ovo desidratado segundo Norberg (2004).

3 Composição básica do produto: sulfato de ferro; sulfato de cobre; óxido de zinco; monóxido de manganês; selenito de sódio; iodeto de cálcio veículo Q.S.P. Níveis de garantia por kg do produto: Mn - $140.000 \mathrm{mg}$ $\mathrm{Zn}-120.000 \mathrm{mg}$; Fe - $100.000 \mathrm{mg}, \mathrm{Cu}-18.000 \mathrm{mg} ; \mathrm{I}-2.000 \mathrm{mg}$; Se $600 \mathrm{mg}$

4 Níveis de garantia por kg do produto: vit. A - 36.000.000 UI; vit. D3 7.400.000 UI; vit. E - 64.000 UI; vit. K3 - 8.000 mg; vit. B12 - 48.000 $\mathrm{mg}$; vit. B1 - $6.400 \mathrm{mg}$; vit. B2 - $20.000 \mathrm{mg}$; vit. B6 - $9.600 \mathrm{mg}$; ácido fólico - $2.800 \mathrm{mg}$; ácido pantotênico - 44.000 mg; ácido nicotínico - 120.000 mg; biotina - $200 \mathrm{mg}$.

5 Sulfaquinoxalina $24 \mathrm{~g}$; diaveridina $12 \mathrm{~g}$; trimetropim 4,8 g. Excipiente q.s.p. $100 \mathrm{~g}$.

6 Bacitracina de zinco.

7 BHT = Butil Hidroxi Tolueno.

8 Inerte = areia

(CRD) e total (CRT) e conversão alimentar (CA) nos períodos de 1 a 2,1 a 3,1 a 4, 1 a 7, 1 a 14 e 1 a 21 dias de idade.

As médias, mínimas e máximas, de temperatura e umidade relativa do ar registradas em aparelho termohigrômetro no interior do galpão em dois períodos diários, às 8 e $16 \mathrm{~h}$, foram de 25 e $30^{\circ} \mathrm{C}$ e 94 e $43 \%$, respectivamente.

Os ovos descartados para o consumo humano foram colhidos diariamente no setor de Avicultura do CFT. O 
Tabela 2 - Composição das rações experimentais fornecidas na fase de 8 a 21 dias de idade ${ }^{1}$

\begin{tabular}{|c|c|c|c|c|}
\hline \multirow[b]{2}{*}{ Ingrediente } & \multicolumn{4}{|c|}{ Nível de ovo desidratado nas dietas ${ }^{2}$} \\
\hline & 0,00 & 0,50 & 1,00 & 1,50 \\
\hline Milho & 59,651 & 59,352 & 59,052 & 58,753 \\
\hline Farelo de soja & 33,955 & 33,456 & 32,957 & 32,459 \\
\hline Calcário & 0,968 & 0,968 & 0,969 & 0,969 \\
\hline Fosfato bicálcico & 1,777 & 1,784 & 1,790 & 1,796 \\
\hline Ovo desidratado ${ }^{2}$ & 0,000 & 0,500 & 1,000 & 1,500 \\
\hline DL-metionina & 0,222 & 0,219 & 0,215 & 0,212 \\
\hline L-lisina. $\mathrm{HCl}$ & 0,174 & 0,176 & 0,173 & 0,170 \\
\hline Óleo vegetal & 2,500 & 2,500 & 2,500 & 2,500 \\
\hline Premix mineral ${ }^{3}$ & 0,050 & 0,050 & 0,050 & 0,050 \\
\hline Premix vitamínico 4 & 0,100 & 0,100 & 0,100 & 0,100 \\
\hline Cloreto de colina, $70 \%$ & 0,080 & 0,080 & 0,080 & 0,080 \\
\hline Sal comum & 0,441 & 0,442 & 0,443 & 0,444 \\
\hline Anticoccidiano 5 & 0,040 & 0,040 & 0,040 & 0,040 \\
\hline $\begin{array}{l}\text { Promotor de } \\
\text { crescimento }^{6}\end{array}$ & 0,015 & 0,015 & 0,015 & 0,015 \\
\hline Antioxidante ${ }^{7}$ & 0,010 & 0,010 & 0,010 & 0,010 \\
\hline Inerte $^{8}$ & 0,017 & 0,308 & 0,606 & 0,902 \\
\hline \multicolumn{5}{|l|}{ Composição química } \\
\hline Proteína bruta (\%) & 20,877 & 20,877 & 20,877 & 20,877 \\
\hline EM (kcal/kg) & 3.000 & 3.000 & 3.000 & 3.000 \\
\hline Cálcio (\%) & 0,939 & 0,939 & 0,939 & 0,939 \\
\hline Fósforo total (\%) & 0,672 & 0,670 & 0,667 & 0,665 \\
\hline Fósforo disponível (\%) & 0,441 & 0,441 & 0,441 & 0,441 \\
\hline Metionina total $(\%)$ & 0,542 & 0,543 & 0,543 & 0,543 \\
\hline Metionina digestível (\%) & 0,513 & 0,514 & 0,514 & 0,515 \\
\hline Met + cis total $(\%)$ & 0,872 & 0,872 & 0,871 & 0,871 \\
\hline Met + cis digestível $(\%)$ & 0,792 & 0,792 & 0,792 & 0,792 \\
\hline Lisina total $(\%)$ & 1,234 & 1,234 & 1,233 & 1,233 \\
\hline Lisina digestível (\%) & 1,119 & 1,119 & 1,119 & 1,119 \\
\hline Treonina total $(\%)$ & 0,801 & 0,802 & 0,803 & 0,803 \\
\hline Treonina digestível (\%) & 0,697 & 0,698 & 0,699 & 0,700 \\
\hline Sódio (\%) & 0,216 & 0,216 & 0,216 & 0,216 \\
\hline Cloro $(\%)$ & 0,296 & 0,296 & 0,297 & 0,297 \\
\hline Potássio (\%) & 0,804 & 0,794 & 0,784 & 0,773 \\
\hline
\end{tabular}

1 Recomendações de Rostagno et al. (2000).

2 Aminoácido do ovo desidratados segundo Norberg (2004).

3 Composição básica do produto: Sulfato de ferro, sulfato de cobre, óxido de zinco, monóxido de manganês, selenito de sódio, iodeto de cálcio, veículo Q.S.P. Níveis de garantia por kg do produto: Mn -140.000 mg;

Zn - 120.000 mg; Fe - 100.000 mg; Cu - 18.000 mg; I - 2.000 mg; Se - 600 mg

4 Níveis de garantia por kg do produto: vit. A - 36.000.000 UI; vit. D3 -

$7.400 .000 \mathrm{UI}$; vit. E $64.000 \mathrm{UI}$, vit. K3 - $8.000 \mathrm{mg}$; vit. B12 - $48.000 \mathrm{mg}$ vit. B1 - $6.400 \mathrm{mg}$; vit. B2 - $20.000 \mathrm{mg}$; vit. B6 - $9.600 \mathrm{mg}$; ácido fólico - 2.800 mg, ácido pantotênico - 44.000 mg; ácido nicotínico - 120.000 mg; biotina - $200 \mathrm{mg}$

${ }^{5}$ sulfaquinoxalina $24 \mathrm{~g}$, diaveridina $12 \mathrm{~g}$, trimetropim 4,8 g. Excipiente q.s.p. $100 \mathrm{~g}$.

6 Bacitracina de zinco

7 BHT = Butil Hidroxi Tolueno.

8 Inerte = areia

conteúdo (gema+clara) foi pesado, colocado em bandejas e mantido em estufa com ventilação forçada a $55^{\circ} \mathrm{C}$ durante 72 horas. Em seguida, o material pré-seco foi retirado, pesado, moído e armazenado em freezer

Diagnósticos de Salmonella ssp. foram realizados no Laboratório de Controle de Qualidade de Alimentos do Centro de Formação de Tecnólogos - CFT, segundo recomendações do Laboratório Nacional de Referência Animal - Lanara (1981). O ovo desidratado foi utilizado na formula- ção das dietas experimentais somente após o resultado negativo para a presença de Salmonella ssp. A composição do ovo desidratado em aminoácidos foi obtida segundo Norberg et al. (2004), enquanto a EMAn e o teor de proteína foram citados por Teixeira et al. (2005).

As análises estatísticas foram realizadas utilizando-se o software SAEG - Sistema para Análises Estatísticas e Genética, versão 5.0, desenvolvido pela Universidade Federal de Viçosa - UFV (1982). Aplicou-se o teste F na comparação de médias e, em seguida, realizaram-se análises de regressão linear e quadrática para estudar os efeitos do fornecimento de ovo desidratado.

\section{Resultados e Discussão}

Os níveis de ovo desidratado influenciaram $(\mathrm{P}<0,05)$, com efeitos linear e quadrático, os consumos de ração diário e total até os 14 dias de idade, respectivamente (Tabela 3). O maior consumo foi observado quando fornecida a ração com $1 \%$ de ovo desidratado e o menor quando fornecida a ração com 1,5\%. Entretanto, aos 21 dias de idade, não houve efeito dos níveis de ovo desidratado sobre os consumos diário e total de ração $(\mathrm{P}>0,05)$. Silva et al. (2006) também observaram efeito semelhante da adição de $0,6 \%$ de ovo desidratado na ração sobre o consumo de ração em pintinhas de 1 a 7 dias de idade. Junqueira et al. (2001), no entanto, constataram efeito contrário, com a redução no consumo, com a adição de 5 a $25 \%$ deste produto na ração de pintos de corte.

Verificou-se efeito significativo $(\mathrm{P}<0,05)$ da adição de ovo desidratado na ração sobre o peso vivo (Tabela 3). Aos 2 e 21 dias de idade, os maiores pesos vivos foram obtidos com $1 \%$ de ovo desidratado na ração, enquanto aos 14 dias de idade nenhuma diferença foi encontrada no peso vivo das aves alimentadas com as rações com 0; 0,5 e 1\% de ovo desidratado. Os piores resultados foram observados com a adição de $1,5 \%$ de ovo desidratado na ração.

O menor peso vivo dos pintos aos 7 dias de idade alimentados com ração contendo 1,5\%, em comparação àqueles alimentados com as rações contendo 0,5 e $1,0 \%$ de ovo desidratado, pode ser atribuído ao nível excessivo de lipídios no lúmen intestinal em uma fase que os pintos não estão plenamente adaptados à digestão de lipídios (Moran, 1985), embora Ribeiro et al. (2006a) tenham observado, aos 2 e 3 dias de vida, maiores pesos vivos com a inclusão de até $4 \%$ de ovo desidratado na ração de pintos. Contrariando esta tendência, Junqueira et al. (2001) verificaram influência negativa da inclusão de 5\% de ovo desidratado em rações sobre o peso vivo de frangos. Silva et al. (2006) observaram 
Tabela 3 - Consumo total de ração total em frangos de corte alimentados com rações contendo ovo desidratado

\begin{tabular}{|c|c|c|c|c|c|}
\hline \multirow{2}{*}{$\begin{array}{l}\text { Variável } \\
\text { Idade (dias) }\end{array}$} & \multicolumn{4}{|c|}{ Ovo desidratado (\%) } & \multirow[b]{2}{*}{$\mathrm{CV}(\%)$} \\
\hline & 0,0 & 0,5 & 1,0 & 1,5 & \\
\hline \multicolumn{6}{|c|}{ Consumo de ração (g/dia) } \\
\hline $2^{1}$ & $6,49 \mathrm{~A}$ & $6,35 \mathrm{AB}$ & $6,65 \mathrm{~A}$ & $6,05 \mathrm{~B}$ & 7,421 \\
\hline $3^{2}$ & $18,06 \mathrm{AB}$ & $18,47 \mathrm{AB}$ & $18,79 \mathrm{~A}$ & $17,94 \mathrm{~B}$ & 5,379 \\
\hline $4^{2}$ & $34,27 \mathrm{AB}$ & $34,57 \mathrm{~A}$ & $34,64 \mathrm{~A}$ & $33,35 \mathrm{~B}$ & 4,337 \\
\hline $7^{1,2}$ & $165,69 \mathrm{~A}$ & $166,39 \mathrm{~A}$ & $170,35 \mathrm{~A}$ & $149,08 \mathrm{~B}$ & 8,983 \\
\hline $14^{1}$ & $709,79 \mathrm{AB}$ & $729,59 \mathrm{~A}$ & $696,24 \mathrm{~B}$ & $696,64 \mathrm{~B}$ & 4,907 \\
\hline 21 & $1.397,29$ & $1.443,47$ & $1.403,63$ & $1.410,33$ & 6,011 \\
\hline \multicolumn{6}{|c|}{ Peso vivo $(\mathrm{g})$} \\
\hline 2 & $51,82 \mathrm{AB}$ & $51,72 \mathrm{~B}$ & $52,26 \mathrm{~A}$ & $51,81 \mathrm{AB}$ & 1,402 \\
\hline 3 & 62,91 & 63,08 & 63,98 & 63,47 & 2,687 \\
\hline 4 & 78,59 & 78,60 & 80,08 & 78,60 & 4,542 \\
\hline $7^{1,2}$ & $178,09 \mathrm{~A}$ & $177,08 \mathrm{~A}$ & $181,79 \mathrm{~A}$ & $162,33 \mathrm{~B}$ & 5,402 \\
\hline $14^{1,2}$ & $491,37 \mathrm{~A}$ & $496,83 \mathrm{~A}$ & $500,64 \mathrm{~A}$ & $475,80 \mathrm{~B}$ & 3,608 \\
\hline $21^{2}$ & $929,36 \mathrm{~B}$ & $949,75 \mathrm{AB}$ & $957,56 \mathrm{~A}$ & $922,82 \mathrm{~B}$ & 3,717 \\
\hline \multicolumn{6}{|c|}{ Ganho de peso $(\mathrm{g})$} \\
\hline 2 & 8,29 & 8,22 & 8,79 & 8,45 & 8,342 \\
\hline 3 & 19,39 & 19,59 & 20,51 & 20,11 & 8,529 \\
\hline 4 & 35,07 & 35,11 & 36,60 & 35,24 & 10,130 \\
\hline $7^{1,2}$ & $134,57 \mathrm{~A}$ & $133,59 \mathrm{~A}$ & $138,32 \mathrm{~A}$ & $118,97 \mathrm{~B}$ & 7,160 \\
\hline $14^{1,2}$ & $447,68 \mathrm{~A}$ & $451,88 \mathrm{~A}$ & $456,83 \mathrm{~A}$ & $431,64 \mathrm{~B}$ & 3,944 \\
\hline $21^{2}$ & $885,49 \mathrm{~B}$ & $904,12 \mathrm{AB}$ & $913,37 \mathrm{~A}$ & $877,92 \mathrm{~B}$ & 3,841 \\
\hline \multicolumn{6}{|c|}{ Conversão alimentar $(\mathrm{kg} / \mathrm{kg})$} \\
\hline $2^{1}$ & $0,786 \mathrm{~A}$ & $0,775 \mathrm{AB}$ & $0,761 \mathrm{AB}$ & $0,720 \mathrm{~B}$ & 9,553 \\
\hline 3 & 0,943 & 0,945 & 0,922 & 0,895 & 9,004 \\
\hline 4 & 0,989 & 0,992 & 0,957 & 0,954 & 10,984 \\
\hline 7 & 1,234 & 1,246 & 1,232 & 1,256 & 7,591 \\
\hline 14 & $1,587 \mathrm{~A}$ & $1,616 \mathrm{~A}$ & $1,525 \mathrm{~B}$ & $1,615 \mathrm{~A}$ & 4,826 \\
\hline 21 & $1,579 \mathrm{AB}$ & $1,598 \mathrm{AB}$ & $1,537 \mathrm{~B}$ & $1,609 \mathrm{~A}$ & 5,961 \\
\hline
\end{tabular}

A,B Médias seguidas de letras maiúsculas diferentes na coluna são estatisticamente distintas pelo teste $F$.

1 Efeito linear $(P<0,01)$

2 Efeito quadrático $(\mathrm{P}<0,01)$.

Consumo de ração:

$\begin{array}{ll}1 \text { a } 2 \text { dias } & \hat{Y}=6,42604+0,466668 x-0,444445 x^{2}\left(R^{2}=0,53\right) \\ 1 \text { a } 3 \text { dias } & \hat{Y}=18,0073+1,87570 x-1,25695 x^{2}\left(R^{2}=0,87\right) . \\ 1 \text { a } 4 \text { dias } & \hat{Y}=34,2177+1,82431 x-1,57639 x^{2}\left(R^{2}=0,94\right) . \\ 1 \text { a } 7 \text { dias } & \hat{Y}=164,267+23,7771 x-21,9653 x^{2}\left(R^{2}=0,85\right) . \\ 1 \text { a } 14 \text { dias } & \hat{Y}=718,982-14,5535 x\left(R^{2}=0,36\right) . \\ \text { Peso vivo: } & \\ 7 \text { dias } & \hat{Y}=176,596+19,1646 x-18,4514 x^{2}\left(R^{2}=0,80\right) . \\ 14 \text { dias } & \hat{Y}=490,015+36,8869 x-30,3093 x^{2}\left(R^{2}=0,90\right) . \\ 21 \text { dias } & \hat{Y}=927,860+80,3413 x-55,1337 x^{2}\left(R^{2}=0,94\right) .\end{array}$

Ganho de peso total:

1 a 7 dias $\hat{Y}=133,080+19,397 x-18,3681 x^{2}\left(R^{2}=0,80\right)$.

1 a 14 dias $\hat{Y}=446,499+36,8618 x-30,2259 x^{2}\left(R^{2}=0,87\right)$.

1 a 21 dias $\hat{Y}=884,344+80,3164 x-55,0504 x^{2}\left(R^{2}=0,92\right)$.

Conversão alimentar:

1 a 2 dias $\hat{Y}=0,396008-0,210413 \times\left(R^{2}=0,89\right)$. 
que a adição de $0,6 \%$ de ovo desidratado na fase pré-inicial não reduziu o peso vivo de pintainhas.

O ganho de peso aos 2, 4 e 21 dias de idade foi maior quando incluído $1 \%$ de ovo desidratado na ração (Tabela 3 ). Aos 7 e 14 dias de idade, não houve efeito significativo da inclusão de $0 ; 0,5$ e $1 \%$ de ovo desidratado na ração sobre esta variável, entretanto, o menor ganho foi observado com $1,5 \%$ de ovo desidratado. Teixeira et al. (2005) utilizaram dois níveis de ovo desidratado (15 e 30\%) em substituição à dieta-referência e constataram que o valor energético do ovo desidratado reduziu com o nível de $30 \%$ em comparação ao nível de $15 \%$, o que pode estar relacionado ao excesso de lipídios da ração com $30 \%$ de ovo desidratado, o que compromete a capacidade dos pintos de aproveitar os nutrientes comsumidos. Assim, parte substancial da ração é perdida nas excretas. Junqueira et al. (2001) também verificaram efeito negativo da inclusão de 5, 10, 15, 20 e $25 \%$ de ovo desidratado, em comparação a uma ração controle, no ganho de peso de pintos de 1 a 21 dias de idade.

O melhor nível de inclusão de ovo desidratado para máximo ganho de peso total até 7 dias de idade foi de $0,53 \%$ de acordo com a equação $\hat{Y}=133,080+19,397 X-18,3681 X^{2}$ (Figura 1).

Segundo a equação $\hat{Y}=884,344+80,3164 X-55,0504 X^{2}$, o nível de ovo desidratado para máximo ganho de peso total até 21 dias de idade foi de $0,73 \%$. Houve efeito significativo dos níveis de ovo desidratado sobre a conversão alimentar (Tabela 3), uma vez que, aos 2 dia, aos 14 e aos 21 dias de idade, a melhor conversão foi obtida com o fornecimento de 0,5 e $1 \%$ de ovo desidratado na ração. As piores conversões foram observadas com o fornecimento das rações controle (sem ovo desidratado) e com 1,5\% desse subproduto. Segundo Teixeira et al. (2006 e 2007), a inclusão de ovo desidratado não afeta a conversão alimentar de aves na fase inicial.

Os resultados de desempenho comprovam que é possível o aproveitamento de ovos descartados das granjas na alimentação de frangos de corte como forma de reduzir a quantidade de resíduos no ambiente e ofertar um ingrediente rico em energia e proteína às aves nas fases inicial e de crescimento (Teixeira et al., 2005).

Não houve efeito significativo do fornecimento de ovo desidratado sobre os pesos de carcaça e peito e de seus respectivos músculos, Pectoralis major e Pectoralis minor, em pintos abatidos aos 3 dias de idade (Tabela 4).

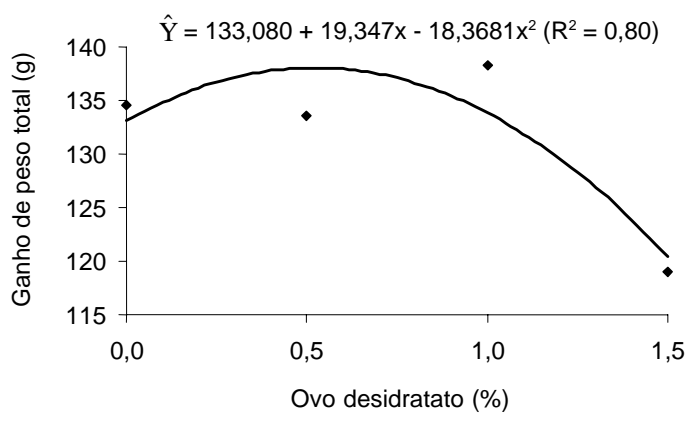

Figura 1 - Ganho de peso total em frangos alimentados com rações contendo ovo desidratado.

Tabela 4 - Pesos de carcaça e peito e dos músculos Pectoralis major e Pectoralis minor de pintos de corte aos 3 dias de idade e pesos das vísceras comestíveis e não comestíveis de frangos de corte alimentados com rações contendo ovo desidratado

\begin{tabular}{|c|c|c|c|c|c|}
\hline \multirow{2}{*}{$\begin{array}{l}\text { Variável } \\
\text { Idade (dias) }\end{array}$} & \multicolumn{4}{|c|}{ Ovo desidratado (\%) } & \multirow[b]{2}{*}{$\mathrm{CV}(\%)$} \\
\hline & 0,0 & 0,5 & 1,0 & 1,5 & \\
\hline Carcaça (g) & 33,5 & 31,98 & 35,71 & 34,75 & 8,58 \\
\hline Peito $(\mathrm{g})$ & 4,33 & 4,55 & 4,98 & 5,05 & 13,25 \\
\hline Pectoralis major $(\mathrm{g})$ & 1,98 & 2,35 & 2,62 & 2,41 & 22,35 \\
\hline Pectoralis minor (g) & 0,563 & 0,625 & 0,508 & 0,495 & 34,765 \\
\hline Trato gastrintestinal (g) & 23,84 & 24,64 & 25,35 & 24,07 & 9,39 \\
\hline Intestino delgado (g) & 9,49 & 10,45 & 10,79 & 10,49 & 11,93 \\
\hline Duodeno $(g)^{1}$ & 1,79 & 1,66 & 1,72 & 1,98 & 17,10 \\
\hline Jejuno $(g)$ & 2,56 & 3,50 & 3,35 & 3,26 & 20,89 \\
\hline Íleo $(g)$ & 2,93 & 2,98 & 2,95 & 2,91 & 13,77 \\
\hline Moela (g) & 4,16 & 4,81 & 4,63 & 4,90 & 12,02 \\
\hline Fígado (g) & 4,44 & 4,46 & 4,19 & 4,50 & 15,12 \\
\hline Bolsa de Fabrício (g) & 0,15 & 0,16 & 0,17 & 0,15 & 35,37 \\
\hline Trato gastrointestinal $(\mathrm{cm})$ & 71,37 & 75,03 & 71,53 & 74,12 & 9,241 \\
\hline Jejuno $(\mathrm{cm})$ & 21,67 & 38,82 & 24,63 & 28,50 & 37,53 \\
\hline Íleo $(\mathrm{cm})$ & 27,53 & 30,53 & 25,35 & 28,80 & 12,40 \\
\hline
\end{tabular}

${ }^{1}$ Efeito quadrático $(P<0,01)$ 
Nesta pesquisa, o fornecimento de ovo desidratado não alterou as medidas determinadas no trato gastrintestinal, com exceção do peso do duodeno, que foi afetado de forma quadrática $(\mathrm{P}<0,05)$ e foi menor quando fornecido $0,98 \%$ de ovo desidratado na ração (Tabela 4), conforme a equação ( $\left.\hat{\mathrm{Y}}=1,79075-0,75866 \mathrm{X}+0,16 \mathrm{X}^{2} ; \mathrm{R}^{2}=0,53\right)$.

Os pesos das vísceras comestíveis e não comestíveis e da bolsa de fabricius não foram afetados pelo fornecimento de ovo desidratado na ração $(\mathrm{P}>0,05)$. A adição do ovo desidratado também não influenciou $(\mathrm{P}>0,05)$ os comprimentos do trato gastrintestinal e do intestino delgado (Tabela 4). Junqueira et al. (2001), avaliando o peso das vísceras comestíveis e os índices morfométricos intestinais de aves aos 4 dias de idade alimentadas com 5, 10, 15 e 20\% de ovo em pó, observaram que o peso e o comprimento do intestino foram menores que os observados em aves alimentadas com dietas à base de milho e farelo de soja. Longo et al. (2005), usando $20 \%$ do ovo em pó na dieta, observaram que não houve diferença significativa do desenvolvimento do intestino delgado das aves aos 1, 4 e 7 dias de idade.

\section{Conclusões}

O nível recomendável de inclusão de ovo desidratado em rações para frangos de corte na fase pré-inicial é de $0,53 \%$ e, na fase inicial, de $0,73 \%$.

\section{Literatura Citada}

AVicultura industrial. Ano Bom, n.11, p.64-69, 2005.

DIBNER, J.J. Early development of the digestive tract and nutritional implications. Poultry Digest, v.5, p.16-19, 1997.

HARMON, B.G.; LATOUR, M.A.; NORBERG, S. [2001]. The use of spray dried eggs as an ingredient in diets for infantile pigs and broilers. Swine Research Report, Purdue University, 2001. p.72. Disponível em: http:<www.ansc.purdue.edu/swine/ swineday/sday02/5.pdf.> Acesso em: 15/3/2004.

JUNQUEIRA, O.M.; ARAÚJO, L.F.; ARAÚJO,C.S.S. et al. Desempenho de frango de corte alimentados com ovo em pó. Revista Brasileira de Ciência Avícola, v.3, n.1, p.65-73, 2001.

LONGO, A.F.; MENTEN, J.F.M.; PEDROSO, A.A. et al. Diferentes fontes de proteína na dieta pré-inicial de frangos de corte. Revista Brasileira de Zootecnia, v.34, n.1, p.112$122,2005$.

MINISTÉRIO DA AGRICULTURA. SECRETARIA NACIONAL DE DEFESA AGROPECUÁRIA. LABORATÓRIO NACIONAL DE REFEREANCIA ANIMAL - LANARA. Métodos analíticos Oficiais para controle de produtos de origem animal e seus ingredientes - II - Métodos físicos e químicos. Brasília: Cap.XXI, p.1-2, 1981.

MORAN, E.T. Digestion and absorption of carbohydrates in fowl and events through perinatal development. Journal of Nutrition, v.115, p.665-674, 1985.

NORBERG, S.E.; DILGER, R.N.; DONG, H. et al. Utilization of energy and amino acids of spray-dried egg, plasma protein and soybeam meal by ducks. Poultry Science, v.83, p.939-945, 2004.

RIBEIRO, M.L.G.; SILVA, J.H.V.; TEIXEIRA, E.N.M. et al. Efeito do tempo de jejum pós-alojamento e inclusão do ovo desidratado em dietas pré-iniciais e iniciais de pintos de corte. Suplemento Revista Brasileira de Ciência e Tecnologia Avícola, v. 8, p.132, 2006a.

RIBEIRO, M.L.G.; SILVA, J.H.V.; TEIXEIRA, E.N.M. et al. Inclusão do ovo desidratado em dietas de frangos de corte de 1 a 21 dias de idade. Revista Brasileira de Ciência e Tecnologia Avícola, v.8, p.131, 2006b.

ROSTAGNO, H.S.; ALBINO, L.F.T.; DONZELE, J.L. et al. Tabelas brasileiras para suínos e aves: composição de alimentos e exigências nutricionais. Viçosa, MG: Universidade Federal de Viçosa, 2000. 141p.

SILVA, J.H.V.; JORDÃO FILHO, J.; SILVA, E.L. et al. Efeito da substituição dos antimicrobianos pelo ovo desidratado na fase pré-inicial de frangas de dois grupos genéticos alojadas em camas nova e reciclada. Revista Brasileira de Zootecnia, v.35, p.2077-2084, 2006.

SCHIMIDT, L.S.; NYACHOTY, C.M.; SLOMINSKI, B.A. et al. evaluation of egg byproducts in diets for early-weaned pigs. Journal of Animal Science, v.8, p.2270-2278, 2003.

TEIXEIRA, E.N.M.; SILVA, J.H.V.; BARROS, L.R. et al. Valor nutritivo do ovo desidratado e do caldo de cana para pintos. Suplemento Revista Brasileira de Ciência e Tecnologia Avícola, v.7, p.130, 2005.

TEIXEIRA, E.N.M.; SILVA, J.H.V.; COSTA, F.G.P. et al. Inclusão do ovo desidratado em rações peletizadas e fareladas para frangos de corte. Revista Brasileira de Zootecnia, v.36, p.1372$1381,2007$.

TEIXEIRA, E.N.M.; SILVA, J.H.V.; FERNANDES, A.C. et al. Efeito do tempo de jejum pós-alojamento, inclusão do ovo desidratado em dietas com e sem antimicrobianos. Suplemento Revista Brasileira de Ciência e Tecnologia Avícola, v. 8, p.129, 2006.

UNIVERSIDADE FEDERAL DE VIÇOSA - UFV. Sistema de Análises Estatísticas e Genéticas (manual do usuário). Versão 5.0. Viçosa, MG: 1982. 49p.

WASHBURN, K.W. Incidence cause and prevention of egg shell breakage in commercial production. Poultry Science, v.61, p.2005-2012, 1982. 